\title{
Assessment of Farm Households' Vulnerability to Desertification in Rural Dry Lands of Katsina State, Nigeria
}

\author{
Olanrewaju Yusuf Yahaya \\ Department of Geography and Regional Planning, Federal University Dutsin-Ma, P.M.B. 5001, \\ Dutsin-Ma, Katsina State, Nigeria, \\ E-mail: yyahaya@fudutsinma.edu.ng \\ Received 31 Jan 2021, Revised 9 Jul 2021, Accepted 20 Jul 2021, Published Aug 2021 \\ DOI: https://dx.doi.org/10.4314/tjs.v47i3.12
}

\begin{abstract}
The purpose of this study was to use a Vulnerability Index (VI) to assess farm households' vulnerability to desertification in Northern Katsina's dry land ecosystem. The specific objectives were to identify socio-economic characteristics of farm households; and determine the degree of their vulnerability to desertification. A systematic random sampling technique was used to select 633 respondents from 18 rural communities across six Local Government Areas (LGAs). Data from 21 indicators for the three components of vulnerability (exposure, sensitivity and adaptive capacity) were used to measure the degree of vulnerability and thus, classify households into less, moderate and highly vulnerable. The study found that households in Jibia LGA were less vulnerable, with a VI of 1.228 , while Kaita, Mashi, and Mai'adua LGAs were moderately vulnerable with VI of $0.523,0.756$, and 0.685 , respectively. Households in Zango and Baure LGAs were found to be highly vulnerable due to poor biophysical conditions, with indices of 1.629 and -1.405 , respectively. Furthermore, while $49 \%$ of the total households sampled were moderately vulnerable to desertification, $30 \%$ were less vulnerable and $21 \%$ were found to be highly vulnerable. As a result, the study recommended that the need for vegetative cover regeneration, soil quality rehabilitation, increased irrigation use, and biomass stability that take into account the vagaries of climate be prioritized in order to support, rescue, and increase the resilience of vulnerable households.
\end{abstract}

Keywords: Adaptation, Desertification, Dry lands, Farm Households, Vulnerability Index.

\section{Introduction}

While most rural communities are thought to be predominantly homogeneous in nature, vulnerability to hazards in general can vary significantly across communities, households, social groups, and even individuals. The term 'vulnerability' has gained more recognition in contemporary studies as an essential part of hazards and risk research including but not limited to ecology, disaster risk management, secure livelihoods, climate change impacts, and drought incidences. In the words of Cutter et al. (2000), vulnerability connotes the susceptibility of a given population, system, or place to harm from exposure to hazards which directly affects the ability to prepare for, respond to, and recover from the hazards and disasters. One of such widely recognized disastrous hazards is desertification. It is generally considered a serious threat to the environment and human welfare which has negative impacts on provision of ecosystem services in dry lands, particularly food and fodder production, and thereby leading to conflicts between pastoral households and sedentary crop producers (Abbass 2012, Dimelu et al. 2016, Majeed and 
Muhammad 2019). In Nigeria, desertification is a major ecological problem of the Northern part of the country especially the dryland areas and, as such, being considered as one of the most pressing environmental problems that constitute serious threats to the welfare of the people living in the Sahelian areas (Nasiru 2007, Olagunju 2015, Elijah et al. 2017). By this, it is regarded as an environmental hazard which people have being trying to cope with, resist and even recover from its impacts. It is therefore, the ability of the people in terms of their capacity to anticipate, cope with, resist and recover from the impacts of desertification that defines their vulnerability in that context. According to the Intergovernmental Panel on Climate Change (IPCC 2012), the components of vulnerability are exposure, sensitivity and adaptive capacity. It indicates that vulnerability is the net effect of adaptive capacity and sensitivity/exposure. It follows that when the adaptive capacity of a household is more than that of its sensitivity and exposure, then the household becomes less vulnerable to hazards, whereas, if a household has only limited capacity to adapt, it becomes vulnerable.

Vulnerability to hazards varies greatly across continents, countries, communities and even individuals. It is considered relatively high in developing countries. For instance, African continent has been highlighted as particularly vulnerable to climate change in the future, primarily due to its low adaptive capacity and its sensitivity to many of the projected changes (IPCC 2007). In Katsina State, as in any other frontline States of Nigeria, the rural population especially the farm households whose livelihoods depend principally on ecosystem and natural resources, are often regarded as the most vulnerable population to desertification than urban population. The incidence of desertification is made very severe in Katsina State by increasing human attempts to exploit the resources of the ecological zone in the face of persistent drought. For instance, human pressure resulting in over grazing and over exploitation of marginal lands particularly in the Northern part of Katsina State has continued to take toll on the environment, resulting in desertification (Katsina State Ministry of Environment 2002). Similarly, Abaje et al. (2012) revealed that the trends and fluctuations of annual rainfall in Katsina and its immediate environs show a decrease of 220.20 $\mathrm{mm}$ at the rate of $3.67 \%$ per annum and, by implication, Katsina area has been experiencing a general decrease in the period of wet season yearly and an apparent increase in desertification process. This situation is deeply concerning and worrisome for the sustainability of human activities, especially as it relates to farming, the main economic activity of the rural people.

Although most rural communities are predominantly homogenous, households within communities may have differing degrees of vulnerability. This is because access to and control over the resources necessary for adaptation also vary within countries, communities and even households. While it is generally recognized that rural population is the most vulnerable to desertification, rural farmers are considered the most important households at risk among the natural resourcedependent categories of rural households vulnerable to desertification. According to this, and in line with Burton et al. (2002) contention that micro-level studies should form the inputs for formulating relevant policies at the national level, it is worth noting that most of the scientific literature and discourses on vulnerability over the last decades have concentrated on contributing to theoretical insights or measurements at the regional or national scale (Brooks et al. 2005, Füssel 2007, Hinkel 2011). Moreover, studies on community vulnerability and adaptation that had been conducted globally and specifically in Africa (Gallopin 2006, Ford 2011, Khan and Salman 2012, Opiyo et al. 2014, Abaje et al. 2015, Savo et al. 2016, Greve et al. 2017) were conducted on climate change impacts and vulnerability. This indicates that much remains unknown regarding micro-level vulnerabilities and adaptation to desertification in Africa, and 
Nigeria in particular. Hence, the need to assess the vulnerability of farming families at the household level in desertification prone areas of Northern Katsina constituted the main crux of this research. Once the degree of vulnerability is known, appropriate specific interventions can be directed towards improving the livelihoods of the vulnerable groups.

\section{Study area}

Katsina State, the study area, was created out of the former Kaduna State on September 23,1987 . It lies between latitudes $11^{\circ} 07^{\prime} \mathrm{N}$ and $13^{\circ} 22^{\prime} \mathrm{N}$ and longitudes $6^{\circ} 52^{\prime} \mathrm{E}$ and $9^{\circ} 20^{\prime} \mathrm{E}$. The State is bordered to the East by Kano and Jigawa States, to the South by Kaduna State, to the West by Zamfara State, and to the north by Niger Republic (Figure 1). The focus of this study was on the Northern fringe of Katsina State where the incidence of desertification is more pronounced and the LGAs that are more vulnerable to desertification as shown in Figure 1 include Baure, Jibia, Kaita, Mai'adua, Mashi, and Zango LGAs. They are situated on the arid zone of the Sahel Savannah agro-ecological belt of Katsina State with a semi-arid continental climate having average annual rainfall ranging from 600 to $700 \mathrm{~mm}$ or less in some LGAs. They have a relatively shorter rainy season of five months and long dry season of seven months. These areas have been grappling with the challenge of desertification every year leading to soil erosion and disruption of the ecosystem (Adamu 2000). The temperature of the area is high especially at the peak of dry season when temperature reaches about $38-40{ }^{\circ} \mathrm{C}$ and above some times (Adamu 2000). The climate of the zone supports mostly savanna vegetation and Sudan savanna is particularly found in Northern Katsina with shrubs and scarce vegetation cover.

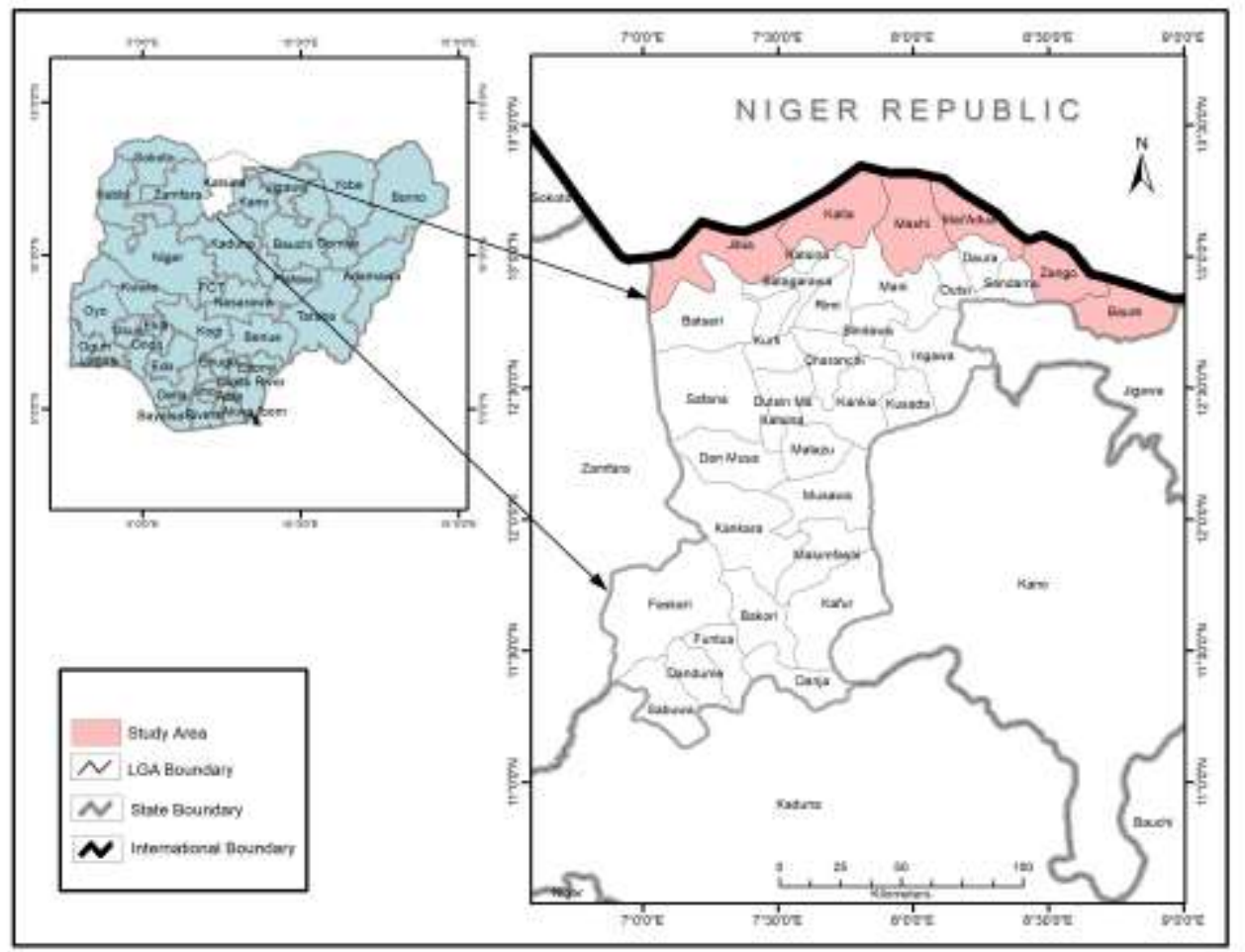

Figure 1: Location of the study area within Katsina State. Source: Adapted and modified from Katsina State Administrative Map, 2018. 
The trees species in the study area are those with deep tap roots that were able to withstand the long dry season. They include Acacia nilotica, Parkiabiglobosa, Faidherbia albida and Adansoniadigitata (Adamu 2000). Katsina State is predominantly rural with a great majority of Hausa-Fulani speaking people and $70 \%$ of its population lives in rural areas. The 2006 population census put the population of Katsina State at 5,792,578 with a total land mass of $24.192 \mathrm{~km}^{2}$. Agriculture is the main economic activity of the people of the study area and the State in general. In the study area as in other parts of the State, agriculture is largely rain-fed. The soil of the area contains drift deposits which are coarser, resulting in light sandy soils of buff or reddish colours of low fertility. They are marginal for efficient arable crop production. Millet and sorghum are the main food crops grown, while the predominant crop mixtures are sorghum, millet, cowpea or groundnut. Livestock production is also widespread in the area as it is known for large production of cattle, goats, sheep, horses, donkeys, and camel.

\section{Materials and Methods}

The study was conducted in February of 2018. The selection of the respondents involved a multi-stage sampling procedure. Firstly, areas that are susceptible to desertification in Katsina State were identified. Six (6) out of the eight LGAs known for the perennial ecological problems of desertification were chosen. They are Baure, Jibia, Kaita, Mashi, Mai'adua, and Zango LGAs. As a result, a purposive sampling was used to select three desertification-prone rural farming settlements from each LGA, yielding a total of eighteen (18) communities across the six LGAs (Figure 2).

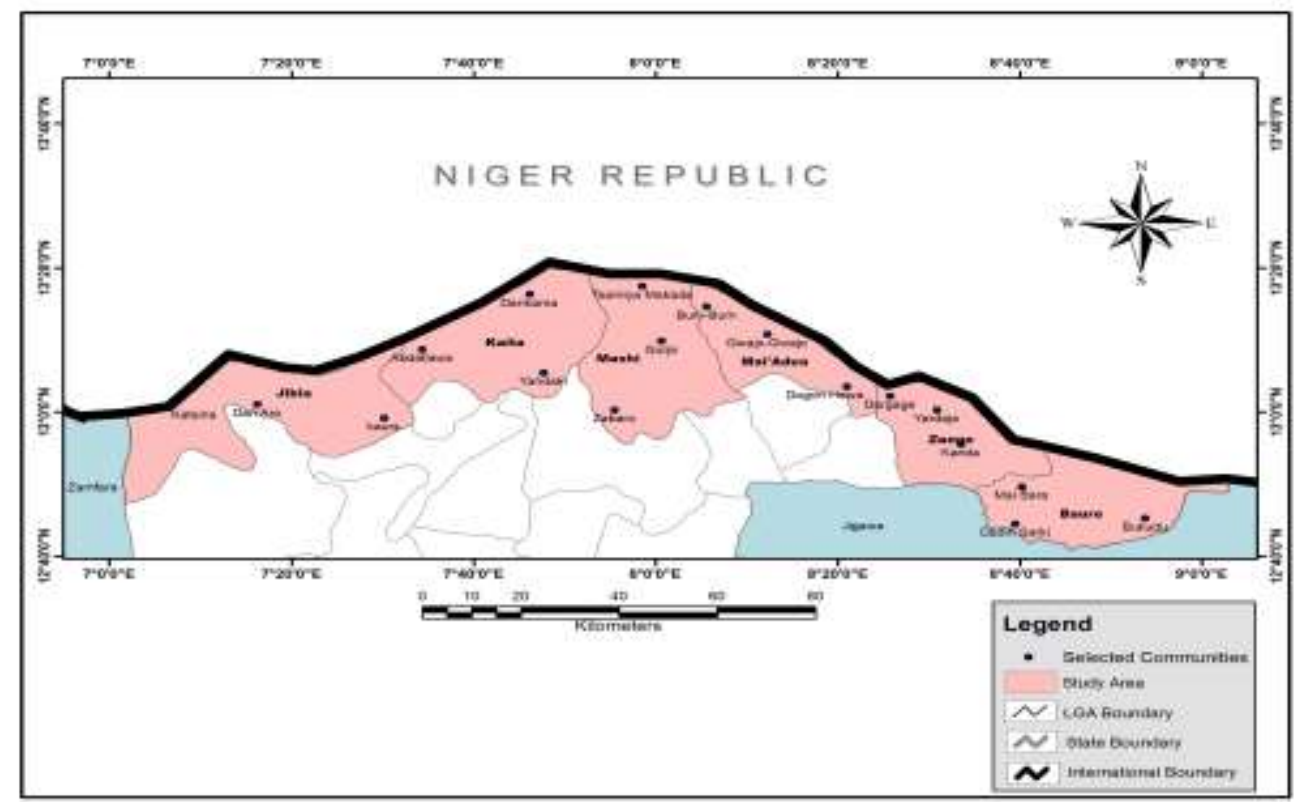

Figure 2: Selected communities across the LGAs of the study.

A total of six hundred and thirty-three (633) respondents were randomly selected based on the proportional population size of each community, making sure that at least $10 \%$ of households from each of the eighteen (18) selected communities were captured. The research instruments used were questionnaires administration and key informant interviews to generate the needed information from respective heads of households. The 
questionnaire was randomly administered to the available heads of households of the selected communities. Information gathered included socio-economic characteristics, perceived causes and effects of desertification, and the degree of vulnerability measured by the sensitivity, exposure and adaptive capacity of household heads. Descriptive analysis entailed the use of tables, frequency counts, percentages and figures. The variables of measurements were then used to calculate Household Vulnerability Index (HVI) and classify households to less, moderate and highly vulnerable. The 21 variables of measurements of vulnerability selected from its three components which are exposure, sensitivity and adaptive capacity were as shown in Table 1 .

Table 1: Variables of measurements of vulnerability

\begin{tabular}{|c|c|c|}
\hline $\begin{array}{l}\text { Component } \\
\text { vulnerability }\end{array}$ & Variables of measurements & Description of the variables \\
\hline $\begin{array}{l}\text { Exposure } \\
\text { (biophysical) }\end{array}$ & $\begin{array}{l}\text { (1) Rainfall } \\
\text { (2) Temperature } \\
\text { (3) Drought } \\
\text { (4) Wind }\end{array}$ & $\begin{array}{l}\text { Variability in annual rainfall } \\
\text { Temperature variability } \\
\text { Extreme events of drought } \\
\text { Noticed unusual change }\end{array}$ \\
\hline $\begin{array}{l}\text { Sensitivity (socio- } \\
\text { economic) }\end{array}$ & $\begin{array}{l}\text { (5) Sex of household } \\
\text { (6) Age of household } \\
\text { (7) Farming status } \\
\text { (8) Educational level } \\
\text { (9) Farm holding size } \\
\text { (10) Household size } \\
\text { (11) Crop production } \\
\text { (12) Early warning information } \\
\text { (13) Experiences in the area }\end{array}$ & $\begin{array}{l}\text { Male/female headed household } \\
\text { Below or above } 45 \text { years } \\
\% \text { of full-time farmers } \\
\% \text { with no primary education } \\
\text { Average farm size } \\
\text { Number of dependents } \\
\text { Total value of crop produced } \\
\text { Access to information } \\
\text { Years of desertification experience }\end{array}$ \\
\hline Adaptive capacity & $\begin{array}{l}\text { (14) Fertilizer supply } \\
\text { (15) Livelihood diversification } \\
\text { (16) Early planting } \\
\text { (17) Insecticide/pesticide } \\
\text { (18) Migration } \\
\text { (19) Credit access } \\
\text { (20) Improved seed varieties } \\
\text { (21) Accumulated assets }\end{array}$ & $\begin{array}{l}\text { Access to fertilizer use } \\
\text { Availability of non-farm income } \\
\text { Engage in early planting } \\
\% \text { of population with access } \\
\text { Movement to cities } \\
\% \text { of population having access } \\
\% \text { of population having access } \\
\text { Ownership of assets }\end{array}$ \\
\hline
\end{tabular}

Source: Author's compilation, 2018.

To measure Vulnerability Index (VI) of rural farm households in the study area, the integrated vulnerability approach as proposed by Madu (2012) and adopted by Tesso et al. (2012) and Opiyo et al. (2014) was used. A set of 21 variables for the three components of vulnerability (exposure, sensitivity and adaptive capacity) was selected for the households of the study area (Table 1). The VI was calculated by the formula given as:

$V I=\left(A_{1} X_{1 j}+A_{2} X_{2 j}+\ldots \ldots+A_{2 n} X_{n j}\right)-\left(A_{n+1}\right.$ $\left.Y_{1 j}+A_{n+2} Y_{2 j}+\ldots . .+A_{n+n} X_{n j}\right)$
Where VI is the Vulnerability Index, Xs are elements of adaptive capacity represented by variables 14-21 (Table 1), Ys are elements of exposure and sensitivity represented by variables 1-4 and 5-13, respectively (Table 1), $X_{1 j}$ represents the mean of $X_{s}$ across the different households, $Y_{1 j}$ is the mean of $Y_{s}$ across the different households with the computation of normalized scores using their mean and standard errors. The Vulnerability Indices of the variables obtained were used to produce an index for each LGA which was 
used to categorise them according to their degrees of vulnerability as shown in Figure 3.

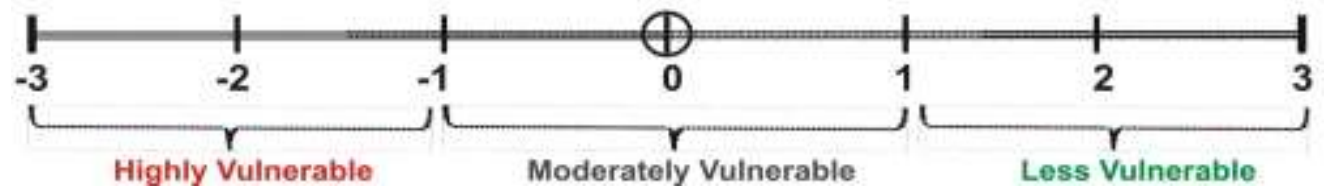

Figure 3: Scale of the degree of vulnerability index.

The Vulnerability Index value range from 3 to +3 , where an index of 1.1 to 3.0 represents the less vulnerable, an index of -1 to +1 stands for the moderately vulnerable and -1.1 to -3 represents the highly vulnerable.

\section{Results and Discussion \\ Background information of respondents}

Table 2 gives the results of the findings on socio-economic characteristics of the farm households. It is revealed that $93 \%$ of households were headed by males, with $65.8 \%$ falling within the age bracket of 36-65 years, are grown adults above 45 years of age. This indicates male-headed dominated households which reflected the cultural household hierarchy in Katsina State where females becoming heads of households is very rare and which is normally attained by the death of the husband. By implication, men of the study area bear the brunt of desertification by headship more than women. Going by educational qualification, $64 \%$ of them had no basic primary education indicating that majority do not have Western education. The average households' size was seven among the $78.5 \%$ category of households having 1-10 family members. This implies that majority of households were having approximately seven dependants and a low educational level. The respondents are full time farmers mainly involved in the production of grains such as millet, sorghum, groundnut and cowpeas. They get involved majorly in mixed cropping of millet/sorghum/cowpeas, with millet cultivation having the most important land use in the area. Based on this finding, it is apparent that majority of the households heavily depend on farming as their source of income and there is modest likelihood of diversified income sources. The findings of this study corresponds to that of Yahaya and Malik (2019), that farming is the predominant occupational system and a basic means of livelihood that support over $80 \%$ of the inhabitants of rural areas in Katsina State, and significantly contributes to household income and livelihood sustainability.

\section{Farm households' vulnerability to desertification}

An analysis of the Vulnerability Indices of the 21 variables of measurements is as shown in Table 3. The results also show the VI in each of the LGAs of study. The results reveal that rainfall has a VI ranging from -0.302 to -2.651 across the six LGAs and, by implication rural household families in all the local governments are vulnerable to decline in rainfall. This indicates that rainfall figures fall within high VI (Figure 3) and hence, makes the people to be highly vulnerable. It follows that the higher the decrease in rainfall amount, the higher the vulnerability. This finding is consistent with the study of Akpodiogaga-a and Odjugo (2010) that the numbers of rain days dropped by $53 \%$ in Northern Nigeria. The decreasing rainfall has led to shortening of the growing season thereby causing reduction in crop production which exposed the farmers to danger.

Evidently, researches such as Abaje et al. (2012) have revealed that the trends and fluctuations of annual rainfall in Katsina and its immediate environs show a decrease of 220.20 $\mathrm{mm}$ at the rate of $3.67 \mathrm{~mm}$ per annum. This implies that the study area has been experiencing a general decrease in the period of wet season yearly and an apparent increase in desertification process. Rain-fed agriculture is the major component of rural livelihood and 
production system in the study area. It follows that any decrease in the rainfall amount will have a resultant effect on crop production. This therefore explains why declining annual rainfall contributes to high vulnerability of the farm households to desertification in the absence of serious irrigation farming to complement the shortfall in rainfall. According to $\mathrm{Li}$ et al. (2018a) which is in line with the finding of this study, drier ecosystems are more sensitive to changes in precipitation and temperature, thereby increasing vulnerability to desertification. Also, the findings of this study are consistent with the findings of Yahaya and Malik (2019) that the phenomenon of desertification with decreasing rainfall and high temperature in Northern Katsina has resulted into loss of farm lands and decrease in crop production, thus reducing the income accruing to farmers.

Table 2: Socio-economic characteristics of respondents

\begin{tabular}{llcc}
\hline $\begin{array}{l}\text { Socio-economic } \\
\text { characteristics }\end{array}$ & Items & Frequency & Percentage \\
\hline Sex & Male & 589 & 93 \\
& Female & 44 & 7 \\
& Total & $\mathbf{6 3 3}$ & $\mathbf{1 0 0}$ \\
\hline Age & $18-35$ & 180 & 28.5 \\
& $36-65$ & 417 & 65.8 \\
& Above 60 & 36 & 5.7 \\
& Total & $\mathbf{6 3 3}$ & $\mathbf{1 0 0}$ \\
\hline Educational qualification & No formal education & 122 & 19.2 \\
& Quranic education & 285 & 45 \\
& Primary education & 86 & 13.6 \\
& Secondary education & 82 & 13 \\
& Tertiary education & 58 & 9.2 \\
& Total & $\mathbf{6 3 3}$ & $\mathbf{1 0 0}$ \\
\hline Size of household & $1-10$ & 497 & 78.5 \\
& $11-20$ & 122 & 19.3 \\
& Above 20 & 14 & 2.2 \\
& Total & $\mathbf{6 3 3}$ & $\mathbf{1 0 0}$ \\
\hline Cropping pattern & Sole & 60 & 9.5 \\
& Mixed & 573 & 90.5 \\
& Total & $\mathbf{6 3 3}$ & $\mathbf{1 0 0}$ \\
\hline
\end{tabular}

Source: Author's field work (2018).

Table 3 also shows the results that the Vulnerability Indices for temperature, drought and wind are equally high across the LGAs except for Jibia local government where temperature and wind have positive indices of 1.843 and 1.632 , respectively which translate to low or minimal vulnerability. This indicates that all the variables of measurements for the biophysical components of vulnerability (rainfall, temperature, drought and wind) were high across all the LGAs. This is in support of the assertion of Oladipo (1993), particularly about drought as a recurrent climatic nemesis occurring with high frequency because of the large inter-annual variability of rainfall in Northern Nigeria. This has subjected the area to frequent drought spells. Drought, temperature, and wind are therefore, products of climatic change which has contributed to the high vulnerability of the farm households of the study area as revealed by the results in Table 3 . 
Yahaya - Assessment of Farm Households' Vulnerability to Desertification in Katsina State ...

Table 3: Measurement of vulnerability of the local government areas of the study

\begin{tabular}{|c|c|c|c|c|c|c|c|}
\hline \multirow[t]{2}{*}{ Components } & \multirow{2}{*}{$\begin{array}{l}\text { Variables } \\
\text { Measurement }\end{array}$} & \multicolumn{6}{|c|}{ Local Government Areas } \\
\hline & & Jibia & Zango & Kaita & Mashi & Baure & Mai'adua \\
\hline \multirow[t]{4}{*}{ Exposure } & Rainfall & -0.302 & -2.651 & -0.902 & -0.744 & -1.532 & -1.714 \\
\hline & Temperature & 1.843 & -2.756 & -1.743 & -1.314 & -2.114 & -2.143 \\
\hline & Drought & -0.210 & -1.945 & -1.034 & -1.142 & -2.325 & -1.314 \\
\hline & Wind & 1.632 & -2.638 & -2.413 & -1.232 & -2.748 & -1.134 \\
\hline \multirow[t]{9}{*}{ Sensitivity } & Sex of household & 1.664 & 1.041 & 1.041 & 1.758 & 1.103 & 1.831 \\
\hline & Age of household & 2.632 & -2.845 & 1.841 & 1.833 & -2.133 & 1.062 \\
\hline & Farming status & -0.641 & -2.795 & -2.614 & -0.721 & -2.100 & -0.714 \\
\hline & Educational level & -1.361 & -2.885 & -0.721 & -1.704 & -1.632 & 1.751 \\
\hline & Farm holding size & 2.147 & -2.678 & 1.622 & 2.102 & -2.014 & 1.632 \\
\hline & Household size & 1.743 & -2.883 & 2.101 & 1.643 & -2.438 & 2.002 \\
\hline & Crop production & 2.854 & -2.748 & 1.000 & 1.843 & -1.432 & 1.342 \\
\hline & Early warning & -2.869 & -2.869 & 1.732 & -0.914 & -2.476 & 1.000 \\
\hline & $\begin{array}{l}\text { information } \\
\text { Experiences in the area }\end{array}$ & -0.101 & 1.231 & -0.742 & 1.003 & -2.810 & -0.912 \\
\hline \multirow{8}{*}{$\begin{array}{l}\text { Adaptive } \\
\text { capacity }\end{array}$} & Fertilizer supply & 1.000 & -2.387 & 1.000 & 2.105 & -2.678 & -0.731 \\
\hline & Livelihood & 2.841 & -0.976 & 1.321 & 1.162 & -1.943 & 1.542 \\
\hline & diversification & 2.476 & 0.156 & 1.742 & 1.124 & 1.212 & 2.005 \\
\hline & Early planting & 2.621 & -2.973 & 2.312 & 1.943 & -2.114 & 2.315 \\
\hline & Pesticides & 2.517 & 0.132 & 0.991 & 2.345 & 0.041 & 1.934 \\
\hline & Migration & 1.730 & 1.043 & 0.932 & 0.931 & 2.131 & 2.741 \\
\hline & Credit access & -0.470 & 1.103 & 2.641 & 0.972 & 1.079 & 0.918 \\
\hline & $\begin{array}{l}\text { Improved seed varieties } \\
\text { Accumulated assets }\end{array}$ & 2.602 & -2.896 & 0.875 & 2.815 & -2.594 & 0.975 \\
\hline \multicolumn{2}{|c|}{ Vulnerability Index } & 1.228 & -1.629 & 0.523 & 0.756 & -1.405 & 0.685 \\
\hline
\end{tabular}

Source: Output of data analysis (2018).

Further breakdown of the results of the analysis based on LGAs shows that Jibia local government has a VI of 1.228, and it is classified as less vulnerable (Table 3 and Figure 3). The results of the variables of measurement of vulnerability in Jibia LGA revealed that age of household heads; crop production, migration, accumulated assets, and livelihood diversification were the main factors responsible for the lesser vulnerability of households of Jibia. All these variables have low Vulnerability Indices that range from 2.517 for migration to 2.854 for crop production. This indicates that majority of the households of Jibia were within the active age bracket (26-45) and the older the population of an area, the higher the vulnerability and vice-versa. Those within the active age bracket are agile and can frequently migrate to other areas in search of job opportunities to complement their farm incomes when the need arise. Ability to migrate and search for means of survival elsewhere will make them to be less vulnerable compared to the elderly of above 50 years whose migrations are somehow restricted. There were also improvements in crop production, and hence contributed to low vulnerability in the area. This could be attributed to the moderate VI of rainfall in Jibia compared to other local governments where the index is high as shown in Table 3. This indicates that rainfall annual amount is more in Jibia than other areas in Northern Katsina. In addition, the Jibia irrigation scheme could also be of help to farmers to boost their crop production which can lead to increase in farm income and accumulated assets and hence making them less vulnerable. 
The results further revealed that Kaita, Mashi and Mai'adua LGAs were moderately vulnerable to desertification. The Vulnerability Indices of the variables in the local governments revealed that the households are highly vulnerable in terms of the general climatic factors (rainfall, temperature, drought and wind) all of which show high indices of vulnerability between -1.1 and -3.0. Similarly, farming status of the households also showed moderate to high Vulnerability Indices of $0.714,-0.721$ and -2.614 for Mai'adua, Mashi and Kaita, respectively (Table 3). Some of the factors that made the people of these local governments to be moderately vulnerable according to the results as contained in Table 3 are early planting, access to credit, accumulated assets, access to pesticides and fertilizer supply. All these variables have low to moderate vulnerability indices, and therefore, responsible for the moderate vulnerability of households. For instance, in Mai'adua local government area, early planting, access to credit, and pesticides have low VI of 2.005, 2.741 and 2.315, respectively. In Mashi local government area, accumulated assets and fertilizer supply have low VI of 2.851 and 2.105, respectively, while the use of pesticides with VI of 2.312 contributes also to the low vulnerability of the farm households. This shows that the people of these areas mostly adopt early planting of crops as a better option for coping with desertification. It equally shows that the people have considerable access to microfinance or community based credit facilities where loans could be assessed to purchase fertilizer among other things to increase crop yields. The loans are equally used to meet up with family expenses when shortfalls in farm income become pervasive. The people are also known for extensive rearing of livestock and with that they have a solid base for accumulated assets. Most of the livestock was sold during financial crises to augment the shortfalls in crop production occasioned by desertification. The factors that contributed majorly to moderate vulnerability of the three local governments
(Kaita, Mashi and Mai'adua) were elements of adaptive capacity as shown by the results. Once the adaptive capacity of the people becomes higher, their vulnerability is lower and vice versa. This explains why the resources of the poor households who are incapacitated by inadequate adaptive measures become prone to the impacts of desertification.

Zango and Baure LGAs were found to be highly vulnerable according to the results in Table 3. The vulnerability indices of the variables of measurements revealed some of the factors that made these two local governments to be highly vulnerable. Apart from the natural factors of low rainfall, high temperature, recurrent drought and wind which are persistent components of high vulnerability over much of the study area, others important factors mainly responsible for the high vulnerability of Zango and Baure local governments include educational level, farm household size, early warning information, farming status as well as livelihood diversification. Educational level had high vulnerability indices of -2.885 and -1.632 for Zango and Baure, respectively. This means that literacy rate among the people was very low thereby leading to high vulnerability. Analysis of the socio-economic characteristics of the respondents contained in Table 2 had earlier revealed that more than $80 \%$ of the respondents had no basic primary education and are not able to read and write. With a low literacy rate, farmers are not innovative enough in farming operations that could increase productivity and hence reduce vulnerability. The Vulnerability Index of average farm size of household is 2.678 for Zango and -2.014 for Baure (Table 3 ). This indicates a high VI which is as a result of small average farm size of household. Other factors that contributed to the high vulnerability are farming status, fertilizer supply and livelihood diversification. Farmers were operating on a full-time basis making farming the main source of livelihood of the people, resulting in over dependency on natural ecosystem for survival. Any small change in climatic conditions will therefore, have a great 
impact on crop production. In addition, there are no other survival options (livelihood diversification) except in few cases when the active adults migrate to cities to engage in menial jobs. The use of fertilizer is also very low in the area due to poverty and the inadequate access to credit facilities. The people are therefore, highly vulnerable due to over dependency on farming with no livelihood diversification coupled with inadequacy of farm inputs (such as fertilizer) that would help in improvements of crop yields in the area.

The vulnerability status of the six LGAs considered is as presented in Figure 4, where the households of Jibia were less vulnerable; Kaita, Mashi and Mai'adua were moderately vulnerable; and Baure and Zango were highly vulnerable.

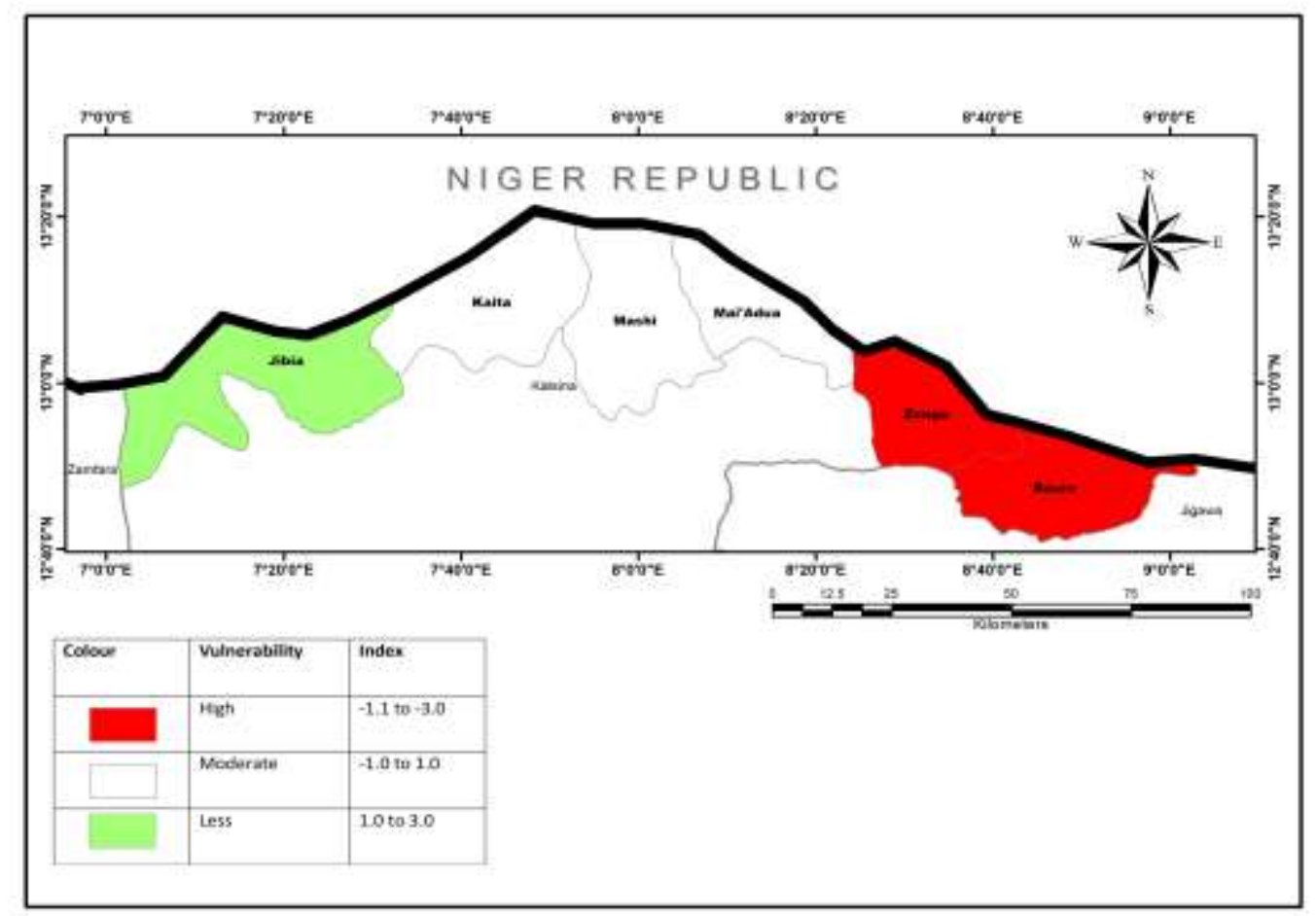

Figure 4: Vulnerability status of the LGAs of the study.

The VI of Jibia local government is 1.228 , which falls between 1.1 to 3.0 value and is classified as less vulnerable; Kaita, Mashi and Mai'aduaLGAs have $0.523,0.756$ and 0.685 indices, respectively and they fall within -1.0 to 1.0 value, which are categorised as moderately vulnerable; and Zango and Baure LGAs have indices of -1.629 and -1.405 , respectively and belong to the class of high vulnerability level within the range of -1.1 to -3.0 values.

The percentage distribution of the sampled households of the six LGAs based on their degrees of vulnerability is as presented in Table 4. 
Table 4: Percentage distribution of households' vulnerability level by LGAs

\begin{tabular}{|l|l|c|c|c|}
\hline & \multicolumn{3}{|c|}{ Vulnerability category } & \\
\hline LGAs & Less & Moderate & High & Sampled household \\
\hline Jibia & $54(53.4 \%)$ & $35(34.7 \%)$ & $12(11.9 \%)$ & 101 \\
Zango & $29(26.4 \%)$ & $38(34.5 \%)$ & $43(39.1 \%)$ & 110 \\
Kaita & $26(25.5 \%)$ & $63(61.8 \%)$ & $13(12.7 \%)$ & 102 \\
Mashi & $20(18.7 \%)$ & $73(68.2 \%)$ & $14(13.1 \%)$ & 107 \\
Baure & $31(30.4 \%)$ & $32(31.4 \%)$ & $39(38.2 \%)$ & 102 \\
Mai'Adua & $30(27 \%)$ & $69(62.2 \%)$ & $12(10.8 \%)$ & 111 \\
\hline Total & $\mathbf{9 0}(\mathbf{1 8 1 . 4})$ & $\mathbf{3 1 0}(\mathbf{2 9 2 . 8})$ & $\mathbf{1 3 3 ( 1 2 5 . 8 )}$ & $\mathbf{6 3 3}$ \\
\hline Average & $\mathbf{3 0 \%}$ & $\mathbf{4 9 \%}$ & $\mathbf{2 1 \%}$ & \\
\hline
\end{tabular}

Source: Author's computation (2018).

From the results (Table 4), 53.4\% of households sampled in Jibia LGA are less vulnerable, $34.7 \%$ are moderately vulnerable, while $11.9 \%$ are highly vulnerable. The breakdown of the vulnerability category of the households sampled in Zango shows that $26.4 \%$ are less vulnerable, $34.5 \%$ are moderately vulnerable, while $39.1 \%$ are highly vulnerable. The analysis in Kaita shows that $25.5 \%$ are less vulnerable, $61.8 \%$ are moderately vulnerable, while $12.7 \%$ are highly vulnerable. In Mashi LGA, $18.7 \%$ of the sampled households are less vulnerable, $68.2 \%$ are moderately vulnerable, while $13.1 \%$ are highly vulnerable. The vulnerability category of the sampled households in Baure LGA revealed that $30.4 \%$ are less vulnerable, $31.4 \%$ are moderate, while $38.2 \%$ are highly vulnerable. In Mai'adua LGA, while $27 \%$ are less vulnerable and $62.2 \%$ are moderately vulnerable, $10.8 \%$ of the sampled households belong to the highly vulnerable category. In all, $30 \%$ of the total sampled households for this study are less vulnerable, $49 \%$ are moderately vulnerable and $21 \%$ are highly vulnerable

Generally, it can be inferred that farm households of the study area are moderately vulnerable to desertification. This is however, in contrast to the general misuse of the advances, status and impacts of desertification and vulnerability of the affected communities as reported in Nigerian press. For examples, newspapers such as Sahara reporters have it in their May $31^{\text {st }}$ of 2009 headline that 'Sahara desert over running Nigeria before our watchful eyes', and Vanguard newspaper of $9^{\text {th } J u l y, ~} 2013$ reported that $43.3 \%$ of land area prone to desertification in Nigeria'. These and many other reported cases give the general public a catastrophic perspective on desertification issues.

\section{Conclusion and Recommendations}

The study has fully established the fact that vulnerability of rural farm households in Katsina to desertification is due to poor physical conditions with moderate or limited ability to manage natural resources upon which their livelihood depends, particularly under changing climatic conditions. Although, desertification presents devastating effects, the households of the study area were generally observed to be moderately vulnerable to desertification. In the arid and semi-arid areas of Nigeria where agricultural production is climate sensitive, the problem of desertification is likely to increase as climate change impacts become more pronounced and droughts emerge as a regular phenomenon in the region with little or no coping measures. In view of this, a sustainable solution to the problems of desertification is a better understanding of the status or level of vulnerability of the susceptible places and people which this study presents.

As a result, it is necessary, as part of the recommendations, to develop effective mitigation and adaptation programmes for long-term resilience of the moderately vulnerable communities, while strategic plans 
and actions are needed to rescue the highly vulnerable communities. Such effective mitigation and adaptation efforts should be directed towards local and regional development policies that would recognize soil and water conservation strategies for achieving sustainable livelihood and agricultural production with emphasis on regeneration of vegetative cover, rehabilitation of soil quality, increase use of irrigation, provision of water catchment, biomass stability and renewable energy sources. Autonomous locally driven adaptation strategies employed by people in the study area should be encouraged, studied, translated to scientific terms, validated, strengthened and incorporated into development planning of existing strategies.

Additionally, Participatory Rural Appraisal (PRA) approach should be considered at the centre of household based strategic plans and actions such as empowering the elderly people, increasing access to credit and farm inputs, creating employment and enhancing access to livelihood diversification to rescue the highly vulnerable and ensure sustainability of their livelihoods.

\section{Acknowledgements}

The support and contributions of research assistances that helped in data collection are greatly acknowledged.

\section{Declaration of conflict of interest}

The author declares that there is no conflict of interest.

\section{References}

Abaje IB, Ati OF and Iguisi EO 2012 Recenttrends and fluctuations of annual rainfall in the Sudano-Sahelian ecological zones of Nigeria: risks and opportunities. $J$. Sustain. Soc. 1(2): 44-51.

Abaje IB, Sawa BA Iguisi EO and Ibrahim AA 2015Aquantitative approach to vulnerability assessment of rural communities to climate change in Kaduna State Nigeria. Nigeria Geographical J.10 (2): 180-195.

Abbass I 2012 No retreat no surrender conflict for survival between Fulani pastoralists and farmers in Northern Nigeria. Eur. Sci. J. 8: 331-346.

Adamu IA 2000 State survey of Katsina, In: Mamman AB, Peter SW and Oyebanji JO (Eds), Nigeria: A people united, A future assured. Vol. 2, Federal Ministry of Information, Abuja, Nigeria pp. 291-302.

Akpodiogaga-a P and Odjugo O 2010 General overview of climate change impacts in Nigeria. J. Human Ecol. 29(1): 47-55.

Brooks N, Adger WN and Kelly PM 2005 The determinants of vulnerability and adaptive capacity at the national level and the implications for adaptation. Global Environ. Change 15(2): 151-163.

Burton I, Huq S Lim B Pilifosova O and Schipper EL 2002 From impacts assessment to adaptation priorities: The shaping of adaptation policy. Climate Policy 2: 145-159.

Cutter SL, Mitchell JT and Scott MS 2000 Revealing the vulnerability of people and places: a case study of Georgetown County, South Carolina. Ann. Assoc. Am. Geogr. 90(4): 713-737.

Dimelu M, Salifu E and Igbokwe E 2016 Resource use conflict in agrarian communities, management and challenges: A case of farmer-herdsmen conflict in Kogi State, Nigeria. J. Rural Stud. 46: 147-154.

Elijah E, Ikusemoran M Nyanganji KJ Mshelisa HU 2017 Detecting and monitoring desertification indicators in Yobe State, Nigeria. J. Environ. Issues Agric. Dev. Countries 9(1): 16-33.

Ford JD, Berrang-FordL and Paterson J 2011 A systematic review of observed climate change adaptation in developed nation. Clim. Change 106(2): 327-336.

Füssel H 2007 Vulnerability: A generally applicable conceptual framework for climate change research. Global Environ. Change 17: 155-167.

Gallopin GC 2006 Linkages between vulnerability, resilience, and adaptive capacity. Global Environ. Change 16(3): 293303.

Greve P, Roderick ML and Seneviratne SI 2017 Simulated changes in aridity from the last glacial maximum to $4 \mathrm{xCO} 2$. Environ. Res. Lett. 12: 114021. 
Hinkel J 2011 Indicators of vulnerability and adaptive capacity: towards a clarification of the science-policy interface. Global Environ. Change 21: 198-208.

IPCC (Intergovernmental Panel on Climate Change) 2007 Climate change 2007-impacts, adaptation and vulnerability. Contribution of working group ii to the fourth assessment report of the IPCC, Cambridge University Press.

IPCC 2012 Managing the risks of extreme events and disasters to advance climate change adaptation. A special report of working groups I and II of the Intergovernmental Panel on Climate Change. Cambridge, UK: Cambridge University Press.

Katsina State Ministry of Environment 2002 Katsina State position paper on desertification control presented at the meeting organized by the Federal Ministry of Environment for the front line States with desertification problems. Held at Katsina on the $16^{\text {th }}$ of May, 2002.

Khan FA and Salman A 2012 A simple human vulnerability index to climate change hazards for Pakistan. Int. J. Disaster Risk Sci. 3(3): 163-176.

Li D, Wu S Liu L Zhang Y and Li S 2018a Vulnerability of the global terrestrial ecosystems to climate change. Glob. Change Biol. 24: 4095- 4106.

Madu IA 2012 Partial vulnerability of rural households to climate change in Nigeria: Implication for internal security. Working paper number 2; May 2012. University of Texas, USA: The Robert S. Strauss Center for International Security and Law.

Majeed A and Muhammad Z 2019 Salinity: A major agricultural problem-causes, impacts on crop productivity and management strategies. In: Hasanuzzaman M Hakeem KR Nahar K and Alharby H (Eds.), Plant Abiotic Stress Tolerance, Springer International Publishing, Cham, Switzerland, pp. 83-99.

Nasiru IM 2007 A comprehensive approach to addressing drought and desertification in Nigeria. Master's thesis, Department of Urban Planning, Faculty of Built Environment, University Teknologi Malaysia.

Oladipo EO 1993A comprehensive approach to drought and desertification in northern Nigeria. Nat. Hazards 8(3): 235-261.

Olagunju TE 2015 Drought, desertification and the Nigerian environment: a review. J. Ecol. Nat. Environ. 7(7): 196-209.

Opiyo EO, Wasonga OV and Nyangito MM 2014 Measuring household vulnerability to climateinduced stresses in pastoral rangelands of Kenya: Implications for resilience programming. Pastoralism: Research, Policy and Practice 4(1): 1-15.

Savo V Lepofsky D Benner JP Kohfeld KE Bailey J and Lertzman K 2016 Observation of climate change among subsistence-oriented communities around the world. Nat. Clim. Change 6: 462-473.

Tesso G, Emana B and Ketema M 2012 Analysis of vulnerability and resilience to climate change induced shocks in North Shewa, Ethiopia. Agric. Sci. 3:871-888.

Yahaya OY and Malik NA 2019 The impact of desertification on rural livelihoods in Baure Local Government Area, Katsina State, Nigeria. In: Chris OI, Dickson DA and Tolulope O (Eds). Geography and sustainable national development, pp. 491-503. Proceedings of the $59^{\text {th }}$ Annual Conference of the Association of Nigerian Geographers (ANG), Department of Geography, University of Ibadan. 